\title{
Tingkat Kepatuhan Pedagang Pangan Jajanan terhadap Cara Produksi Pangan yang Baik
}

\author{
Ema Komalasari ${ }^{1}$, Dina Widiawati ${ }^{1}$ \\ ${ }^{1}$ Program Studi Teknologi Pangan, Fakultas Sains dan Teknologi, Universitas Al Azhar Indonesia, \\ Kompleks Masjid Agung Al Azhar, Jl. Sisingamangaraja, Jakarta, Indonesia 12110 \\ Penulis untuk Korespondensi/E-mail: ema.komala@uai.ac.id
}

\begin{abstract}
Abstrak - Makanan jajanan dikonsumsi oleh sekitar 2,5 miliar orang diseluruh dunia setiap harinya. Namun, pengetahuan pedagang tentang keamanan makanan masih rendah dan memberikan risiko keamanan pangan. Penelitian ini bertujuan untuk menentukan tingkat kepatuhan pedagang makanan pada cara produksi pangan yang baik (CPPB). Survei dirancang untuk 50 pedagang kaki lima berdasarkan 7 elemen, yaitu lokasi, peralatan, penggunaan air, perilaku pedagang, proses, sistem penyimpanan, dan pengelolaan limbah. Sebanyak $62 \%$ pedagang menjual makanan ringan atau makanan tradisional, 32\% pedagang menjual minuman, dan $6 \%$ menjual produk non-makanan. Semua penjual minuman berstatus cukup patuh terhadap CPPB. Sebanyak 33,33\% dari penjual makanan ringan atau makanan tradisional tidak mematuhi CPPB, dengan 17,64\% dari pedagang tidak mematuhi CPPB meskipun mereka telah mengikuti pelatihan keamanan makanan sebelumnya. Sebagian besar titik kritis disebabkan oleh sistem penyimpanan yang buruk, peralatan kotor, perilaku penjual yang buruk, dan proses pengolahan yang buruk.
\end{abstract}

Abstract - Street foods are consumed by around 2,5billion people around the world every day. However, the vendor's knowledge about food safety is still low and givefood safety risk. The study was aimed to determine the level of compliance food vendors on the implementation of good manufacturing practices. A survey was designed to 50 street vendors based on 7 elements, which were location, equipment, water usage, vendors' behavior, process, storage system, and waste management. The vendors were $62 \%$ selling a snack or traditional food, 32\% selling beverages, and 6\% selling non-food products. All beverages vendors had the status of quite obedient to GMP. As many as 33,33\% of snack or traditional food vendors were not compliant with GMP, with $17,64 \%$ of vendors having not compliant withGMP even though they had attended food safety training before. Most of the critical missing points were caused by the poor storage system, dirty equipment, poor vendors' behavior, and poor processing process.

Keywords-Compliance, Food safety, GMP, Street food.

\section{PENDAHULUAN}

$\mathrm{P}$ angan (makanan) jajanan merupakan makanan yang menjadi kebutuhan bagi banyak masyarakat, dengan segmentasi seperti pelajar di tingkat sekolah, mahasiswa di perguruan tinggi, sampai dengan pekerja (pegawai) di suatu institusi. Pangan jajanan didefinisikan sebagai makanan dan minuman yang dipersiapkan dan/atau dijual oleh pedagang kaki lima di jalanan dan di tempat-tempat keramaian umum lain yang dikonsumsi tanpa pengolahan atau persiapan lebih lanjut [1]. Data menunjukkan bahwa ada sekitar 2,5 Miliar orang mengonsumsi pangan jajanan diseluruh dunia setiap harinya [2]. Pangan jajanan yang baik adalah pangan jajanan yang sehat dan aman untuk dikonsumsi yang dapat memberikan manfaat, salah satunya adalah untuk menjaga produktivitas dan memberikan energi bagi tubuh untuk bekerja sehingga pangan jajanan harus terhindar dari berbagai kontaminasi yang dapat menimbulkan bahaya bagi orang yang memakannya.Tidak semua makanan yang dikonsumsi oleh masyarakat aman. Makanan yang dikonsumsi dapat mengandung bahaya mikrobiologis, seperti tercemar oleh bakteri dan dapat menjadi penyebab sakit atau masalah kesehatan lain. Salah satu masalah kesehatan akibat mengonsumsi makanan adalah keracunan makanan. Penelitian menunjukkan $70 \%$ kejadian keracunan dalam hal ini yang terjadi di Amerika Utara, 
disebabkan oleh konsumsi pangan yang disiapkan diluar rumah (pangan jajanan) [3].

Di Indonesia, makanan merupakan penyebab tertinggi insiden keracunan nasional pada tahun 2016, yaitu sebanyak 135 jumlah insiden dan sebanyak 22,95\% sumber keracunan berasal dari pangan jajanan [4]. Minuman berwarna dan sirup menempati urutan pertama pangan jajanan yang tidak memenuhi syarat mikrobiologis disusul oleh produk minuman es lainnya, kemudian jelly atau agar-agar, dan terakhir bakso [5]. Pengolahan dan penyiapan pangan jajanan seharusnya mengikuti cara produksi pangan yang baik (CPPB) yang diperuntukkan bagi industri rumah tangga dan persyaratan higiene sanitasi makanan jajanan sesuai Kepmenkes RI No 942/Menkes/Sk/VII/2003. Cara produksi pangan yang baik untuk industri rumah tangga diatur dalam Peraturan Kepala BPOM RI No 03.1.23.04.12.2206 Tahun 2012. Sekitar $71,96 \%$ pedagang pangan jajanan diketahui belummemiliki pengetahuan keamanan pangan yang baik dan hanya $28,04 \%$ saja yang memiliki pengetahuan keamanan pangan yang baik [6].

Beberapa penelitian mengenai tingkat kepatuhan pedagang telah dilakukan di Indonesia, tetapi penelitian-penelitian tersebut masih terbatas pada beberapa wilayah tertentu, seperti penelitian yang telah dilakukan di wilayah Bogor [7]. Wilayah lain di Indonesia juga perlu dikaji tingkat kepatuhannya untuk mengetahui bagaimana kondisi higiene dan sanitasi di wilayah tersebut serta mengetahui bagaimana kepatuhan pedagang terhadap CPPB. Tujuan khusus penelitian adalah untuk mengetahui tingkat kepatuhan para pedagang Paguyuban Raden Patah yang merupakan perkumpulan kelompok pedagang yang berjualan di sepanjang ruas Jalan Raden Patah, Kebayoran Baru, Jakarta Selatan. Konsumen yang disasar oleh para pedagang adalah mahasiswa UAI, siswa sekolah Al-Azhar Pusat, pegawai Kementerian PUPR, pegawai Telkom, dan masyarakat lainnya.

Sampai saat ini belum ada penelitian terkait analisis tingkat kepatuhan para pedagang Paguyuban Raden Patah terhadap CPPB.Padahal, informasi terkait kepatuhan pedagang tersebut hasilnya dapat dijadikan tolok ukur untuk pengambilan keputusan selanjutnya, seperti, apakah pedagang memerlukan pendampingan kebersihan serta sanitasi atau tidak.Hasil penelitian juga dapat dijadikan sebagai bahan dasar untuk penelitian lanjutan berupa analisis keberadaan jenis bakteri pencemar dalam pangan jajanan serta titik kritis sumber pencemarannya.

\section{METODE}

\section{Tempat dan Waktu Penelitian}

Penelitian dilaksanakan pada Bulan FebruariOktober 2019.Responden penelitian berjumlah 50 dan merupakan pedagang pangan jajanan yang tergabung dalam Paguyuban Raden Patah, berlokasi di sepanjang Jalan Raden Patah Kecamatan Selong Jakarta Selatan.

\section{Tahapan Penelitian}

Penelitian dilakukan dengan menggunakan kuesioner survei dan kuesioner observasi. Penelitian dilakukan dalam 3 tahap, yaitu: (1) Penyusunan kuesioner survei dan kuesioner observasi; (2) Pengambilan data dengan cara wawancara dan observasi; (3) Pengukuran kepatuhan pedagang.

\section{Pengambilan dan Pengolahan Data}

Kuesioner survei disusun mengacu kepada materi dalam Keputusan Menteri Kesehatan Republik Indonesia Nomor 942/Menkes/SK/VII/2003 mengenai Pedoman Persyaratan Higiene Sanitasi Makanan Jajanan [7]. Kuesioner survei meliputi informasi mengenai: (a) produk, (b) tempat dan waktu berjualan, (c) bahan baku yang digunakan, (d) penyimpanan bahan, (e) proses penyajian dan pendistribusian bahan baku, dan (f) kemasan. Sementara kuesioner observasi meliputi: (a) lokasi dan fasilitas berjualan, (b) peralatan, (c) suplai air atau sarana penyediaan air, (d) perilaku pekerja, (e) proses pengolahan dan penyimpanan, dan (f) pembuangan sampah.

Pengukuran tingkat kepatuhan pedagang dilakukan terhadap 3 kriteria penilaian, yaitu tingkat pendidikan, lama bekerja, serta keikutsertaan dalam pelatihan keamanan pangan. Hasil kuesioner digunakan untuk mengetahui tingkat kepatuhan pedagang dalam melaksanakan CPPB selama proses pengolahan makanan jajanan yang terbagi dalam 3 hasil pengamatan, yaitu Patuh, Agak Patuh, dan Tidak Patuh. Penetapan keriteria kepatuhan tersebut didasarkan kepada jumlah ketidaksesuaian minor, mayor, serius, dan kritis seperti pada Tabel 1 . 
Tabel 1. Penentuan kepatuhan pedagang

\begin{tabular}{lcccc}
\multirow{2}{*}{ Tingkat Kepatuhan } & \multicolumn{4}{c}{ Jumlah maksimal ketidaksesuaian } \\
\cline { 2 - 5 } & MI & MA & SR & KR \\
\hline Patuh & 1 & $1-2$ & 1 & 0 \\
Agak Patuh & 1 & $3-4$ & $2-5$ & $1-3$ \\
Tidak Patuh & 1 & $5-8$ & $6-11$ & $4-11$ \\
\hline
\end{tabular}

Keterangan:

MI=ketidaksesuain Minor; MA=ketidaksesuain Mayor; $\mathrm{SR}=$ ketidaksesuaian Serius; $\mathrm{KR}=$ ketidaksesuain Kritis

\section{HASIL DAN PEMBAHASAN}

\section{Karakteristik Pedagang Pangan Jajanan}

Hasil penelitian menunjukkan bahwa sebanyak $62 \%$ (31) responden berjualanan pangan jajanan kategori makanan, $32 \%$ (16) berjualanan pangan jajanan kategori minuman, dan 6\% (3) responden berjualan produk non pangan. Berdasarkan hasil survei, pangan jajanan kategori makanan yang dijual oleh responden setidaknya terdiri dari 10 jenis, seperti kelompok nasi dan lauk (nasi goreng, nasi rames), soto, gado-gado/ketoprak, ayam/lele, siomay/batagor/dimsum, mie ayam, sate, bubur ayam, bakso, dan lainnya. Sebaran untuk setiap jenis makanan dapat dilihat pada Gambar 1A. Pangan jajanan kategori minuman terdiri dari 4 jenis, yaitu es kelapa muda, es podeng, jus, serta minuman kemasan dengan data sebaran disajikan pada Gambar 1B.
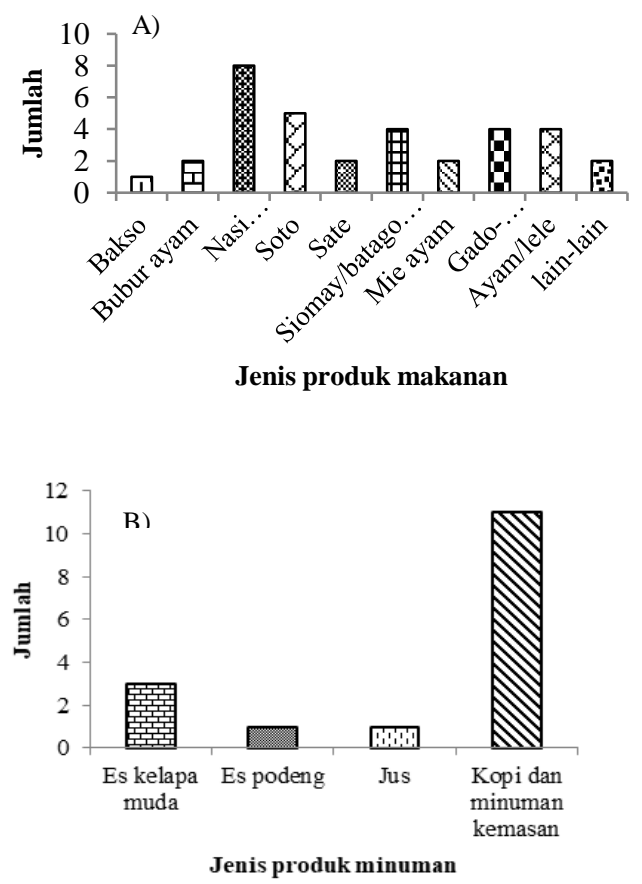

Gambar 1.Jenis Pangan Jajana
Hasil survei yang telah dilakukan, rata-rata usia responden terbayak adalah 40-49 tahun (48.94\%), dan rata-rata pendidikan terakhir responden adalah Sekolah Dasar (SD). Data karakteristik responden disajikan pada Tabel 2.

Tabel 2. Karakteristik Pedagang Pangan Jajanan

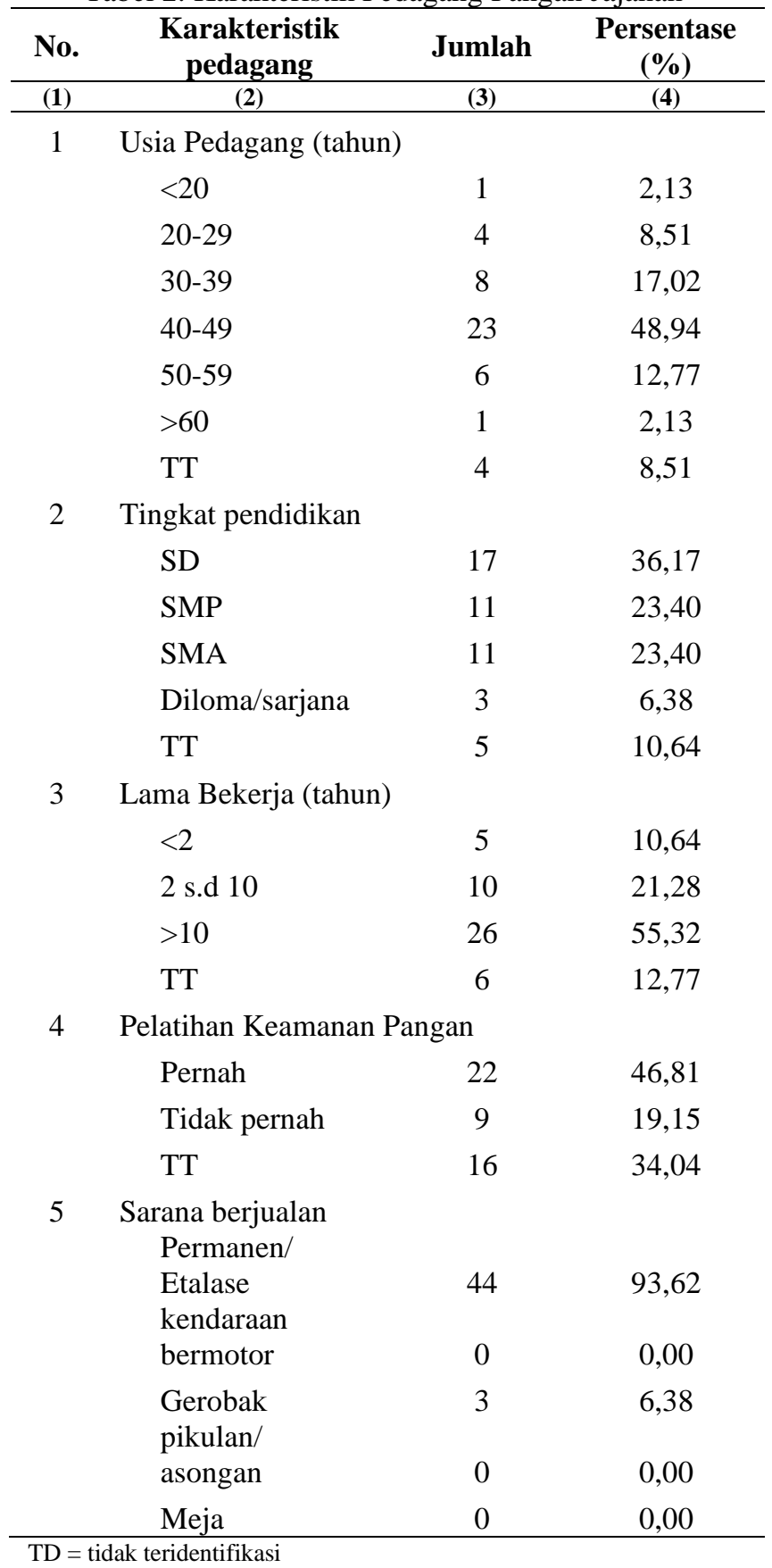

Menurut UU Tenaga Kerja No 13 Tahun 2003, usia produktif seorang tenaga kerja yaitu antara 15 - 64 tahun. Sebanyak $46,81 \%$ responden pernah mendapatkan pelatihan atau penyuluhan mengenai keamanan pangan dengan rerata lama berjualan lebih dari 10 tahun (55,32\%). Rata-rata para responden menggunakan etalase sebagai sarana 
berjualan $(93,62 \%)$ dan hanya 3 responden $(6,38 \%)$ menggunakan gerobak sebagai sarana berjualannya.

\section{Tingkat Kepatuhan Pedagang}

Pengukuran kepatuhan responden yang terbagi dalam 3 kriteria, yaitu kriteria patuh, agak patuh, dan tidak patuh di dasarkan pada jumlah ketidaksesuaian elemen yang diperiksa pada lembar kuesioner observasi. Jenis ketidaksesuaian terdiri dari ketidaksesuaian minor (MI), ketidaksesuaian mayor (MA), ketidaksesuaian serius (SR), dan ketidaksesuaian kritis (KR).

Hasil observasi menunjukkan bahwa ketidaksesuaian kritis rata-rata disebabkan karena tempat penyimpanan bahan pangan yang kotor serta penggunaaan peralatan yang sudah berkarat dan kotor. Sementara itu ketidaksesuain serius disebabkan karena perilaku pedagang yang masih belum menggunakan celemek dan tutup kepala, serta proses pengolahan pangan yang masih kurang baik. Hasil penelitian ini sejalan dengan penelitian yang dilakukan oleh [8] dimana tingkat kepatuhan pedagang sangat rendah pada penggunaan pakaian pelindung, seperti celemek.

Berdasarkan hasil pengukuran, pedagang kategori minuman menunjukkan hasil pengukuran agak patuh (100\%) terhadap CPPB (Gambar 2A), baik itu dari tingkat pendidikan SD, SMP, maupun SMA (tidak ada pedagang kategori minuman lulusan diploma/sarjana). Sementara itu, untuk kategori pedagang makanan (Gambar 2B), tingkat pendidikan diploma/sarjana masih menunjukkan pengukuran tidak patuh, yaitu sebesar 33,33\%. Hasil pengukuran menunjukkan bahwa tingkat pendidikan belum tentu akan mempengaruhi tingkat kepatuhan pedagang tersebut, sama halnya dengan keikutsertaan dalam pelatihan keamanan pangan (Gambar 3A dan 3B).

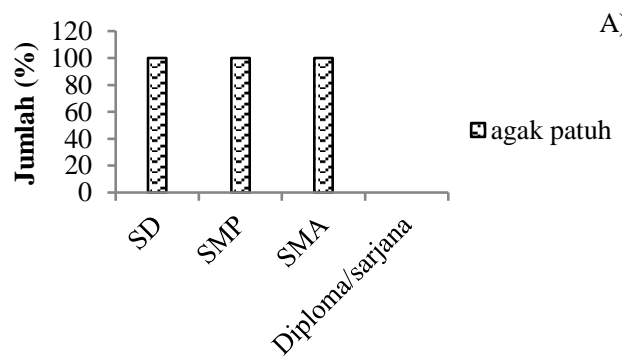

Tingkat pendidikan

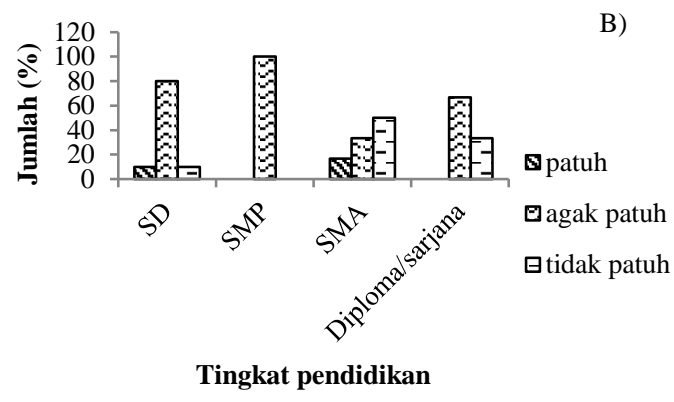

Gambar 2. Tingkat kepatuhan berdasarkan tingkat pendidikan kategori pedagang minuman (A) dan pedagang makanan $(\mathrm{B})$.

Idealnya, tingkat pendidikan pedagang menunjukkan efek positif pada pengetahuan zat terlarang dan kebersihan makanan dan sanitasi [9]. Pernyataan tesebut sesuai dengan penelitian yang dilakukan oleh Rahayu et al. [7] terhadap pedagang minuman es di kota Bogor, dimana pedagang dengan tingkat pendidikan diploma/sarjana menunjukkan hasil pengukuran patuh sebesar $84,62 \%$ terhadap CPPB, sementara lulusan SD dan SMP/SMA menunjukkan hasil pengukuran tidak patuh sebesar $80,00 \%$ dan $80,60 \%$ secara berurutan. Pada Gambar 3 dapat dilihat bahwa pedagang yang pernah mengikuti pelatihan juga dapat menunjukkan hasil pengukuran tidak patuh $(17,64 \%)$ terhadap CPPB.
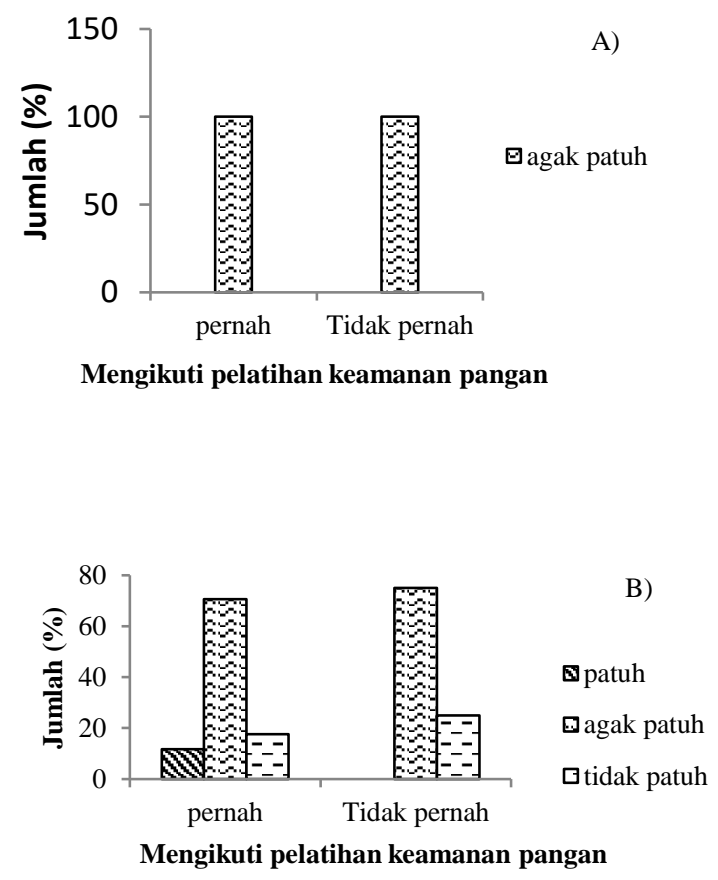

Gambar 3. Tingkat kepatuhan berdasarkan keikutsertaan dalam pelatihan keamanan pangan kategori pedagang minuman (A) dan pedagang makanan (B) 
Berdasarkan hasil observasi mengenai lama waktu bekerja (Gambar 4), juga menunjukkan bahwa lama waktu bekerja tidak menjamin pedagang mengolah dan memproduksi pangan jajanan dengan baik. Sebanyak $25 \%$ pedagang yang sudah berjualan selama lebih dari 10 tahun masih menunjukkan hasil yang tidak patuh terhadap CPPB. Hal ini menunjukkan perlunya pelatihan serta edukasi kepada para pedagang mengenai pemahaman CPPB serta pengujian lebih lanjut terhadap sampel pangan jajanan yang dijual.

Salah satu faktor yang menjadi penyebab ketidakpatuhan tersebut adalah dikarenakan sumber daya yang melakukan proses pengolahan pangan jajanan (orang yang menyajikan) bukan orang yang sama yang telah mendapatkan pelatihan keamanan pangan. Berdasarkan hasil wawancara, sering kali pedagang sebagai pemilik, meminta bantuan orang lain (pegawai) untuk menyajikan pangan jajanan. Hal ini menunjukkan perlunya pembinaan kepada para pedagang serta orang yang menyajikan pangan jajanan dan pembinaan tersebut harus dilakukan secara rutin dalam rentang waktu tertentu. Sesuai dengan hasil penelitian [10] yang juga menyarankan hal yang sama.
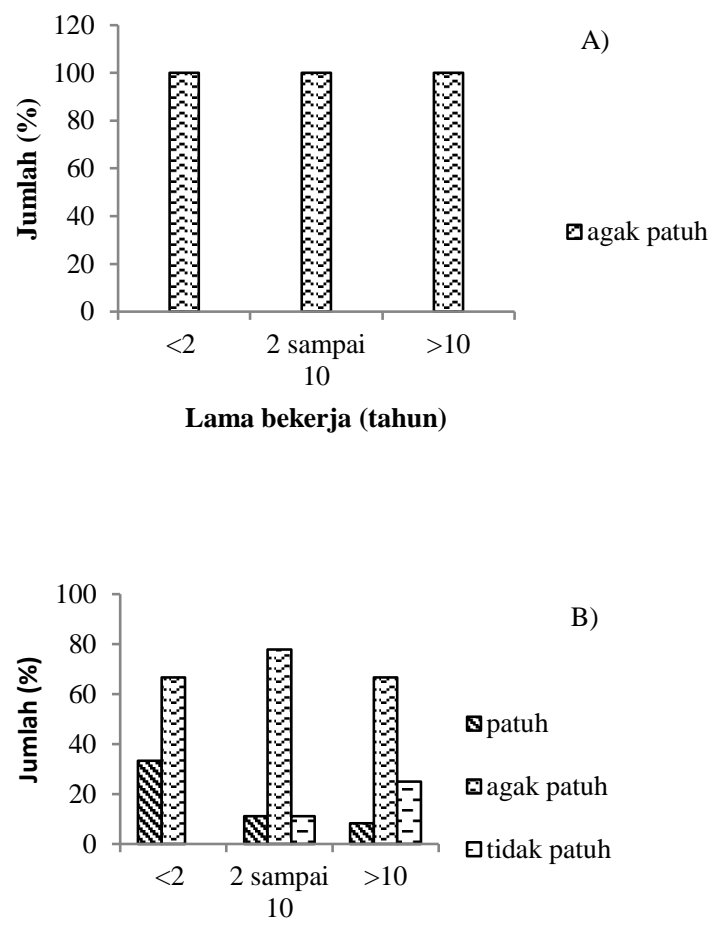

lama bekerja (tahun)

Gambar 4. Tingkat kepatuhan berdasarkan lama bekerja kategori minuman (A) dan makanan (B)

\section{KESIMPULAN}

Hasil penelitian menunjukkan bahwa tingkat kepatuhan pedagang Paguyuban Raden Patah kategori minuman menunjukkan hasil pengukuran agak patuh (100\%) baik berdasarkan tingkat pendidikan, lama bekerja, serta keikutsertaan dalam pelatihan kemanan pangan. Sementara itu untuk pangan jajanan kategori makanan, pengukuran tingkat kepatuhan menunjukkan hasil yang beragam. Berdasarkan tingkat pendidikan, pedagang menunjukkan hasil patuh terhadap CPPB sekitar 10\% dan 16\% untuk tingkat pendidikan SD dan SMA secara berurutan. Berdasarkan keikutsertaan dalam pelatihan keamanan pangan, pedagang kategori makanan hanya menunjukkan hasil pengukuran patuh sebesar $11,76 \%$ dan lama waktu bekerja menunjukkan hasil kepatuhan beragam dan tidak menunjukkan kecenderungan hasil pengukuran patuh pada pedagang yang sudah berjualan selama lebih dari 10 tahun. Sebanyak $25 \%$ pedagang yang sudah berjualan selama lebih dari 10 tahun masih menunjukkan hasil yang tidak patuh terhadap CPPB.Berdasarkan hasil penelitian tersebut, pedagang Paguyuban Raden Patah masih perlu mendapat binaan terkait keamanan pangan serta CPPB.Pembinaan harus dilakukan secara rutin mengingat kemungkinan terjadinya perubahan atau pergantian sumber daya manusia yang mengolah pangan jajanan.Pembinaan dapat dilakukan baik oleh pemerintah, dalam hal ini Dinas Kesehatan maupun oleh instansi pendidikan, seperti Universitas Al Azhar Indonesia yang berada di kawasan seputar Raden Patah.

\section{UCAPAN TERIMA KASIH}

Terima kasih peneliti sampaikan kepada Lembaga Penelitian dan Pengabdian Masyarakat Universitas Al Azhar Indonesia (LP2M UAI) atas pendanaan penelitian skema Stimulus Research Grant 2019.

\section{REFERENSI}

[1] World Health Organization, Food Safety Unit , Peryaratan Utama Keamanan Makanan Pejalan Kaki Lima diterjemahkan oleh SEAMEO TROPMED Regional Center for Community Nutrition. Jakarta: UI, 1996.

[2] Food and Agriculture Organization, World Hunger Report. (2011) High Valatile Price set to Continue. [Online]. http://www.fao.org/fcit/food- 
processing/street-foods/en/

[3] B. Chapman, T. Eversley, K. Fillion, T. Maclaurin, and D. Powell, "Assessment of food safety practices of food service food handlers (risk assessment data): testing a communication intervention (evaluation of tools).," J Food Prot, vol. 73, no. 6, 2010.

[4] Badan Pengawas Obat dan Makanan. (2013) Laporan Tahunan 2012. [Online]. http://www.pom.go.id/ppid/rar/LAPTAH201 3.pdf

[5] Badan Pengawas Obat dan Makanan. (2014) Laporan Tahunan 2013. [Online]. http://www.pom.go.id/ppid/rar/LAPTAH201 3.pdf

[6] Anjani Anggitasari, "Pengaruh Program Keamanan Pangan di Sekolah Terhadap Pengetahuan Penjaja Pangan Jajanan dan Siswa Sekolah Dasar," Institut Pertanian Bogor, Bogor, Skripsi 2014.

[7] Winiati Pudji Rahayu, Qonitatin Wafiyah, Siti Nurjanah, and Caecillia Chrismi Nurwitri, "Tingkat Kepatuhan Pedagang Minuman Es terhadap Cara Produksi Pangan yang Baik di Kota Bogor," Industria: Jurnal Teknologi dan Manajemen Agroindustri, vol. 6, no. 3, 2017.
Priscilla, and S. Nyaw, "Food hygiene and Safety Practices among Street Food Vendors: An Assessment of Compliance, Institutional and Legislative Framework in Ghana," Scientific \& Academic Publishing, vol. 4, no. 6, 2014.

[9] C. Wariyah, S. H. C. Dewi U. Nasikhin, "Hubungan Tingkat Pendidikan Pedangang dengan Higiene Sanitasi Makanan Jajan Anak Sekolah Dasar di Kabupaten Kulon Progo-DIY," Jurnal AgriSains, vol. 4, no. 7, September 2013.

[10] Y. Adjrah, K. Soncy, K. Anany, and K. Blewussi et all, "Socio-economic profile of street food vendors and microbiological quality of ready-to-eat salads in Lome," International Food Research Journal, vol. 20, no. 1, pp. 65-70, 2013.

[8] I. Monney, D. Agyei, B. S. Ewoenam, C. 